\title{
CLEAN AIR AS AN EXPERIENCE GOOD IN URBAN CHINA
}

\author{
Matthew E. Kahn \\ Weizeng Sun \\ Siqi Zheng \\ Working Paper 27790 \\ http://www.nber.org/papers/w27790
NATIONAL BUREAU OF ECONOMIC RESEARCH
1050 Massachusetts Avenue
Cambridge, MA 02138 \\ September 2020, Revised December 2020
}

The views expressed herein are those of the authors and do not necessarily reflect the views of the National Bureau of Economic Research.

NBER working papers are circulated for discussion and comment purposes. They have not been peerreviewed or been subject to the review by the NBER Board of Directors that accompanies official NBER publications.

(C) 2020 by Matthew E. Kahn, Weizeng Sun, and Siqi Zheng. All rights reserved. Short sections of text, not to exceed two paragraphs, may be quoted without explicit permission provided that full credit, including (c) notice, is given to the source. 
Clean Air as an Experience Good in Urban China

Matthew E. Kahn, Weizeng Sun, and Siqi Zheng

NBER Working Paper No. 27790

September 2020, Revised December 2020

JEL No. Q52,Q53

\begin{abstract}
$\underline{\text { ABSTRACT }}$
The surprise economic shutdown due to COVID-19 caused a sharp improvement in urban air quality in many previously heavily polluted Chinese cities. If clean air is a valued experience good, then this short-term reduction in pollution in spring 2020 could have persistent mediumterm effects on reducing urban pollution levels as cities adopt new "blue sky" regulations to maintain recent pollution progress. We document that China's cross-city Environmental Kuznets Curve shifts as a function of a city's demand for clean air. We rank 144 cities in China based on their population's baseline sensitivity to air pollution and with respect to their recent air pollution gains due to the COVID shutdown. The largest experience good effect should take place for cities featuring a high pollution sensitive population and where air quality has sharply improved during the pandemic. The residents of these cities have increased their online discussions focused on environmental protection, and local officials are incorporating "green" industrial subsidies into post-COVID stimulus policies.
\end{abstract}

Matthew E. Kahn

Department of Economics

Johns Hopkins University

3100 Wyman Park Drive

Baltimore, MD 21211

and NBER

mkahn10@jhu.edu

Weizeng Sun

Central University of Finance and Economics

39 South College Road, Haidian District

Beijing, 100081, China

sunweizeng@gmail.com
Siqi Zheng

Sustainable Urbanization Lab

Center for Real Estate

Department of Urban Studies and Planning

Massachusetts Institute of Technology

Cambridge, MA 02139

sqzheng@mit.edu 


\section{Introduction}

In recent years, China's cities have enjoyed economic growth and declining urban air pollution. While economic growth rates varied across cities and regions, the nation's economy as a whole was growing at a rate of roughly $6 \%$ per year over the last five years. Over the years 2015 to 2019 , air pollution has declined annually by $6.9 \%$ in the average city and by $8.1 \%$ in the big cities.

In early 2020, urban air pollution declined in China due to the COVID-19 induced economic shutdown (He et al. 2020). ${ }^{1}$ In the first three months of 2020, the $\mathrm{PM}_{2.5}$ concentration in 285 Chinese cities declined by $11.9 \%$ (with a standard deviation of $18.1 \%)$ relative to the same period in last year. These gains were not uniformly distributed. Some cities, such as Baoding and Xingtai in the Hebei Province, experienced large pollution reductions (roughly $25 \%$ ) from an initial high pollution level of $80 \mu \mathrm{g} / \mathrm{m}^{3}$ in recent years.

In this paper, we study how the early 2020 economic shutdown influences urban China's air quality, citizen environmental engagement, and the nation's regulatory and industrial policy dynamics. A stationary Environmental Kuznets Curve (EKC) yields the empirical prediction that when a developing country economy experiences a "V" shaped economic recovery that pollution will follow similar dynamics and may even rise with ongoing economic growth (Grossman and Krueger 1995). ${ }^{2}$ A local official in a developing country city might even choose to relax environmental regulations during an economic slowdown if he believes that such regulations hinder economic growth (Selden and Song 1995).

In contrast, if clean air is a valued experience good, then the reduction in pollution in spring 2020 could have persistent effects on future urban pollution levels even if the local economies fully recover from the recent recession. In China's polluted cities, blue skies represent a new good. Until they experience persistent air quality gains, urban

\footnotetext{
${ }^{1}$ He et al. (2020) defines "city lockdown" when the following three measures are all enforced: (1) prohibition of unnecessary commercial activities for people's daily lives, (2) prohibition of any type of gathering by residents, (3) restrictions on private (vehicles) and public transportation.

${ }^{2}$ A strict adherent to the view that there is a stable Environmental Kuznets Curve would posit that a city initially located to the left of the turning point, moves down the hill as per-capita income declines and then moves back up the hill as the economy recovers.
} 
residents may under-estimate their own valuation of this new good. Research on experience goods have studied optimal pricing of such goods. Firms that market new products have incentives to initially price them at a low level to stimulate demand and to give consumers "a taste" of the new product (Riordan 1986, Shapiro 1983). We know of no analogous research exploring the implications of local public goods improvements as "experience goods".

A "silver lining" of the COVID-19 pandemic is to offer millions of Chinese urbanites this clean air experience. While China does not hold direct elections, the Chinese people now have much more freedom to express their opinions online and in social media on environmental issues (which are not very sensitive as compared to other political topics). Urban leaders are increasingly held accountable to their citizens' voice because of the rising information transparency. They are evaluated by the central government for political promotion. The criteria for promotion include social stability and environmental targets as well as local economic growth (Zheng et al. 2014). Both online and offline protests are regarded as threats to social stability. The local official performance criteria provides ambitious local leaders with career concerns to consider adopting "green policy"; especially if local residents increasingly desire such policies.

The clean air as an experience good hypothesis posits that the demand for increased regulation will take place in those cities that both enjoy increased short run access to cleaner air and where the population is more sensitive to pollution exposure. This experience effect can vary by city. In those cities where people exhibit a stronger demand for cleaner air, we predict an even greater "experience good" effect as the COVID shutdown cleans up the air.

In a recent research, we have used the content of social media "tweets" in China to measure for each city, to what extent local air pollution lowers residents' sentiment. Using this city level index to measure the local population's pollution sensitivity, we identify those cities whose residents have revealed that they face the highest marginal sentiment cost due to pollution (Zheng et al. 2019).

In arguing that the COVID-19 induced shutdown may accelerate pollution reduction progress in China's most polluted cities, we need to address the counter- 
factual of how pollution would have evolved in different Chinese cities if the COVID19 shock had not occurred. We study this by first examining recent urban pollution dynamics over the years 2015 to 2019 across China. We explore the key roles of industrial activity, the transport sector and the home sector in driving these dynamics. We then build on the work of He et al. (2020) to explore how the recent COVID-19 shock affected pollution dynamics.

In the last section of the paper, we use several new data sets to explore the nascent demand for more intense environmental regulations. We rank 144 cities in China based on their population's baseline sensitivity to air pollution and with respect to their recent air pollution gains due to the COVID shutdown. The largest experience good effect should take place for cities featuring a high pollution sensitive population and where air quality has sharply improved during the pandamic. For these cities, we document that in mid-2020 the local population has increased the discussion of environmental protection on the Internet, and local officials are incorporating "green" industrial subsidies into post-COVID stimulus policies. If these regulations are effective, then this will shift the EKC down and lead to a time series path featuring less pollution as economic development takes place (Dasgupta et al. 1998).

\section{Recent Trends in Urban Air Pollution in China}

We start by presenting recent trends in air pollution across China's cities over the years 2015 to 2019 . The pollution data reports each city's $\mathrm{PM}_{2.5}$ concentration level based on the real time platform managed by the China Environmental Monitoring Station network. ${ }^{3}$ The data are released daily. We calculate each city's annual mean value. Cities with larger populations have higher average pollution levels at the start of the period but have enjoyed greater pollution reductions over time than smaller cities. Smaller cities have also enjoyed air pollution reductions. During a time of economic

\footnotetext{
3 The quality of China's official air quality data has been improved significantly in the last few years, as documented by recent studies. For instance, Liang et al. (2016) found that the US PM2.5 monitors show measured values highly consistent with those measured at China's Ministry of Environmental Protection PM 2.5 monitors located nearby. Stoerk (2016) compared the air quality data via Benford's Law which suggests that misreporting of air quality data for Beijing has likely ended in 2012.
} 
and population growth, China's pollution levels have declined $15 \mu \mathrm{g} / \mathrm{m}^{3}$ on a base of $55 \mu \mathrm{g} / \mathrm{m}^{3}$ (See Figure A1).

Since big cities are richer, local leaders are more likely to enforce stringent environmental regulations (Grossman and Krueger 1995, Selden and Song 1995). When cities differ with respect to their environmental regulatory enforcement, this raises the possibility that footloose polluting industries will relocate to poorer cities that have less stringent regulations, which leads to the "domestic pollution haven" problem (Zheng et al. 2014). In Figure A2, we document the decline in the share of local output from manufacturing in both big and small cities. Big cities have experienced a larger decline. The transition to services and high tech in China's major cities is an important factor that mirrors the transition that occurred in U.S cities (Kahn 1999). The nation's industrial policy has contributed to this geographic shift. The 13th Five-Year Plan (2016-2020) offers forward guidance in determining the spatial distribution of industrial growth. ${ }^{4}$ Given that air pollution has declined in recent years in both big and small cities and in rich and poor cities, this suggests that any industrial composition shifts (i.e the local Bartik trends) has been offset by technique effects such that pollution per unit of economic activity declines.

To explore recent changes in the urban population's exposure to pollution, we calculate the urban population's distribution of pollution exposure in 2015 and 2019. In each year, we tabulate the annual mean pollution data and weight the data by the city's population. Figure 1 reports these two cumulative distribution functions (CDF). Define $\mathrm{X} 80$ as the $80^{\text {th }}$ percentile of the CDF in 2015. X80 indicates that $20 \%$ of the total urban population lived in a city whose average pollution level was equal to or greater than X80. We find that there have been large reductions in pollution exposure to the dirtiest air.

\footnotetext{
${ }^{4}$ According to the plan, large cities and cities in the eastern region focus on the development of high-tech industries, while middle-sized and small cities and cities in the central and western regions are responsible for the traditional manufacturing industry. From 2015 to 2018, the average drop in the share of manufacturing in total GDP of Chinese cities was 3 percentage points (equals to $6.8 \%$ of the mean manufacturing share in 2015). 178 cities experienced decline, and 99 cities experienced increase in this share. More than half of the cities with an increasing manufacturing share are in the western region.
} 


\section{// Insert Figure 1 about here //}

In the year 2015 , roughly $20 \%$ of Chinese urbanites were exposed to less than 40 units of $\mathrm{PM}_{2.5}$. In the year 2019, this percentage grew to almost $60 \%$. The median Chinese urbanite was exposed to just over 50 units of pollution in 2015 while the median person was exposed to 35 units in $2019 .{ }^{5}$ The large distance between the two cumulative distribution functions highlights the significant pollution gains enjoyed by those who live in moderately polluted areas (by way of comparison Los Angeles features a $\mathrm{PM}_{2.5}$ average level of roughly 20). The Figure highlights that even at the high quantiles of the pollution exposure distribution that there has been significant air pollution exposure progress.

\section{Increasing Public Demand for Clean Air Shifts the Environmental Kuznets}

\section{Curve}

\subsection{Measuring Clean Air Demand Using Internet Search Data}

Traditional revealed preference methods rely on annual data such as real estate prices or survey data asking people to state their quality of life priorities. Scholars have also studied the demand for self-protective goods such as masks and air filters and studied how the demand varies across China (Sun et al. 2017, Ito and Zhang 2020, Barwick et al. 2018).

Rising access to real time "big data" provides new facts about how local pollution and climate conditions affect our quality of life. In recent research, we have used billions of social media messages posted on the equivalent of China's Twitter to explore how the population's sentiment (expressed happiness) is affected by pollution and heat (Zheng et al. 2019). People from different cities in China vary with respect to how sensitive they are to air pollution. Zheng et al. 2019 measures this by estimate a city specific partial derivative of happiness (as revealed by social media content analysis)

\footnotetext{
${ }^{5}$ It is important to note that these calculations do not incorporate private averting behavior (Sun et al. 2017). We also do not incorporate within city variation in pollution and the geographic distribution of people within the city.
} 
with respect to that city/day $\mathrm{PM}_{2.5}$ (the "sentiment-pollution" elasticity) ${ }^{6}$.

In that study, the researchers use their 144 city sample to estimate a second stage regression to understand the correlates of this pollution sensitivity. The relationship between city income and pollution sensitivity is monotonically positive - people are more sensitive to pollution in richer cities. At the same time, very dirty and clean cities have a relatively higher elasticity compared to cities in the intermediate pollution range. One explanation for this fact is that people who dislike air pollution most move and live in cleaner cities, and at the same time, people in dirtier cities come to recognize the health risks associated with the long-term pollution exposure.

Using these city specific estimates of the sentiment-pollution elasticity, we divide cities into above median and below median elasticity groups, and test whether the time trends are equal for the two sets of cities over the years 2015 to 2019 .

We estimate equation (1) using city/year data to test whether cities with above median sentiment for avoiding pollution have a steeper negative time trend. Intuitively, we test if we observe a steeper decline in pollution in cities where residents have a greater demand for clean air. We test if $\alpha_{2}<0$.

$$
\begin{aligned}
\text { Pollution }_{i t} & =\alpha_{0}+\alpha_{1} \cdot \text { Trend }_{t}+\alpha_{2} \cdot H S_{i} \cdot \text { Trend }_{t}+\lambda \cdot X_{i t} \\
& + \text { city fixed effects }+\varepsilon_{i t}
\end{aligned}
$$

In equation (1), $H S$ is a dummy variable, which equals 1 if the "sentiment-pollution" elasticity of city $i$ is higher (than the median value), and 0 otherwise. The sample is restricted to the 144 cities whose "sentiment-pollution" elasticities have been estimated by Zheng et al. (2019).

The regression results are presented in Table 1. As shown in columns (1) and (2),

\footnotetext{
${ }^{6}$ In Zheng et al. (2019), they divide the full sample of city-day observations into 144 city subsamples and estimate the following equation using a fixed effect regression approach for each city $i$. This procedure generates a marginal city-specific partial derivative of sentiment with respect to $\mathrm{PM}_{2.5}$ - the "sentiment-pollution" elasticity, $\varphi_{1, i .}$. It is expected to be negative - all else equal, people are more likely to be unhappy on days when their city's pollution level is higher.$$
\text { Sentiment }_{i t}=\varphi_{0}+\varphi_{1} \cdot \text { Pollution }_{i t}+\varphi_{2} \cdot X_{i t}+\text { date fixed effects }+v_{i t}
$$

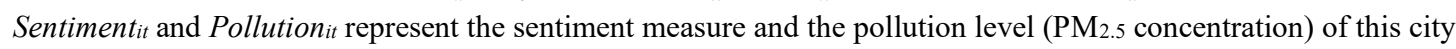
$i$ on day $t$, respectively. We include other variables $X_{i t}$ which represents the city's weather conditions, and date fixed effects.
} 
$\mathrm{PM}_{2.5}$ declined by $8.0 \%$ per year on average in these 144 cities from 2015 to 2019 . The decline rate is $7.5 \%$ per year in lower sentiment-pollution elasticity cities and $8.8 \%$ in the high elasticity cities. The results suggest that cities where the population is more susceptible to pollution have experienced a larger improvement in air quality. The high anti-pollution sentiment cities tend to be the relatively rich cities.

\section{// Insert Table 1 about here //}

As Chinese urbanites have grown richer and more educated, this group should increasingly demand "blue skies". The subset of urbanites who live in the most pollution sensitive cities should be most responsive and place more pressure on local leaders (Zheng et al. 2014).

To explore this hypothesis, we use Internet data to measure the bottom-up push from the public for environmental protection and how this varies across time by city. We use "environmental protection" as the keyword to create an environmental attention index (Baidu_index) at the city level using Baidu platform (http://index.baidu.com/v2/index.html\#/). ${ }^{7}$ Specifically, the Baidu_index = total entries of the key word "environment protection" in the Baidu search engine divided by the total population. This variable is measured in the number of entries per million people. This index reflects the public attention devoted to environment protection for each city in a given year.

We study the yearly environmental attention index's dynamics using Equation (2) (with the same specification as Equation (1)). In column (3) of Table 1, we find that it increases from 2015 to 2019 after controlling for climate and a city's inherent characteristics, and urbanites in cities featuring a higher sentiment-pollution elasticity are paying more and more attention to environmental protection. In column (4), we document that in the cities with a larger higher environmental attention index, they have

\footnotetext{
7 In China, The central government's Ministry of Enviromental Protection and local governments' Environmental Protection Bueaus play the central role in pollution regulation. People use "environmental protection" on the social media or all kinds of Internet forums when they discuss the current environmental policies from those government bureaus or express their desire for such policies.
} 
experience an air quality improvement in the next year.

$$
\begin{aligned}
\text { Baidu_index }_{i t} & =\beta_{0}+\beta_{1} \cdot \text { Trend }_{t}+\beta_{2} \cdot H S_{i} \cdot \text { Trend }_{t}+\chi \cdot X_{i t} \\
& + \text { city fixed effects }+\mu_{i t}
\end{aligned}
$$

\subsection{The Dynamic Environmental Kuznets Curve}

We test if the cities with a greater environmental awareness have an earlier EKC turning point such that subsequent economic growth is negatively correlated with pollution. Following the research design in Zheng et al. (2014), we estimate equation (3) below in order to examine how the shape of the EKC and in particular the GDP "turning point" varies as a function of the public sentiment-pollution elasticity and their demand for environmental protection. In equation (3), the unit of analysis is a city/year. Following the EKC literature, we include a quadratic in a city's per-capita real GDP. ${ }^{8}$ These variables proxy for the city's enforcement of environmental regulation and the quality of the local capital stock. We expect that in richer cities that environmental regulations are more stringently enforced and that the capital stock is newer and more energy efficient.

$$
\begin{aligned}
\text { Pollution }_{i t} & =\gamma_{0}+\gamma_{1} \cdot \ln \left(G D P P C_{i t}\right)+\gamma_{2} \cdot \ln \left(G D P P C_{i t}\right)^{2} \\
& +\gamma_{3} \cdot \ln \left(P O P_{i t}\right)+\lambda \cdot X_{i t}+\text { year fixed effects }+\varepsilon_{i t}
\end{aligned}
$$

In equation (3), we also control for the city's population level (the scale of activity) and the weather conditions in that city/year and year fixed effects to control for the macro conditions of the economy at that time.

In column (1) of Table 2, the results are based on the sample of 285 cities. We find evidence of an inverted- $U$ relationship between the city's $\mathrm{PM}_{2.5}$ concentration and percapita GDP. The turning point is about 48.8 thousand Yuan (7,839 US dollars, in 2015

\footnotetext{
8 We recognize that Hilton and Levinson (1998) recommend using a more flexible functional form for per-capita income. In Appendix Table A1, we report such additional regressions. Our main findings are robust to such more flexible specifications.
} 
constant price. ${ }^{9}$ We also calculate the count of cities whose per-capita GDP is such that they have passed the EKC turning point. During the years 2015-2018, 47\% cities have passed the EKC turning point. In columns (2) and (3), we use the median value of the sentiment-pollution elasticity to divide the city sample into two subsamples. We find that the two subsamples have similar turning points, but in the subsample with the more pollution sensitive population, a larger proportion of cities pass this turning point. In columns (4) and (5), we find that cities with stronger bottom-up push for environmental protection have a much earlier turning point (RMB 37,423 vs. RMB 73,786), and also have a larger proportion of passing the turning point. These results support the claim that cities with a higher Baidu environmental attention index have an earlier EKC turning point.

// Insert Table 2 about here //

\section{The Impact of the COVID Induced Shutdown on Pollution Dynamics}

4.1 Estimating the Air Pollution Decline During the COVID Induced Shutdown in China

We use the variation induced by the COVID shutdown to provide new insights about the distribution of pollution dynamics across China's cities. Panel A in Figure A3 shows the timeline around the 2020 Chinese New Year (CNY). The traditional CNY holiday (when almost all production activities pause) would end seven days since the CNY's Eve, which is Jan $31^{\text {st }}$ in year 2020. However, due to the COVID pandemic, 29 provinces (out of 31 provinces) in China mandated businesses to not resume work before Feb $10^{\text {th }}$ at the earliest. ${ }^{10}$ This unexpected post-CNY holiday shutdown provides us with the opportunity to identify the determinants of air pollution in China.

Panel B in Figure A3 presents the trends of air pollution before and after the

\footnotetext{
$9 \$ 1=$ RMB 6.23, in 2015 .

10 The left two provinces (Qinghai and Tibet) set Feb $3^{\text {th }}$ as the earliest day of resuming work, and the actual first day depended on the city-specific situation around that time.
} 
Chinese New Year in 2017 through 2020. Air pollution since the CNY's Eve of 2020 was significantly lower than that of the same periods of 2017-2019. This divergence becomes much larger after the end of traditional CNY holiday.

To quantify the reduction in pollution associated with the shutdown, we use city/year/day pollution data and present an event study in a difference-in-differences setting (Equations (4) and (5)):

$$
\begin{aligned}
\text { Pollution }_{i t} & =\theta_{0}+\theta_{1} \cdot \text { Shutdown }_{t}+\theta_{2} \cdot \text { Shutdown }_{t} \times \text { year } 2020 \\
& + \text { fixed effects }+\varepsilon_{i t}
\end{aligned}
$$

$$
\begin{aligned}
\text { Pollution }_{i t} & =\delta_{0}+\delta_{1} \cdot S F_{-} \text {holiday }_{t}+\delta_{2} \cdot \text { COVID_shutdown }_{t} \\
& +\delta_{3} \cdot \text { year } 2020+\delta_{4} \cdot S F_{-} \text {holiday }_{t} \times \text { year } 2020 \\
& +\delta_{5} \cdot \text { COVID_shutdown } \\
& \times \text { year } 2020 \\
& + \text { fixed effects }+\varepsilon_{i t}
\end{aligned}
$$

We restrict the sample to twenty days before and sixteen days after the CNY's Eve (until Feb. $10^{\text {th }}$, the first day of re-open). In Equation (4), Shutdown=1 indicates the seventeen days since the CNY's Eve. year2020=1 indicates year 2020. We choose 2018 and 2019 as the benchmark years. In Equation (5), SF_holiday=1 indicates the eight days since the CNY's Eve, also the regular CNY holiday, so this period for all the three years has very little production activity. COVID_shutdown $=1$ indicates the $8^{\text {th }}$ to $16^{\text {th }}$ days since the CNY's Eve, which are the unexpected shutdown days in 2020 due to COVID, but they are regular workdays in 2018 and 2019. Therefore, the extra decline of air pollution in the first period in 2020 was mainly due to the complete pause of holiday activities such as driving for family reunion, net of the possible increase of home cooking (which might add pollution); while the extra deline in the second period was attributed to the shutdown of production activity and the associated travel demand decline, net of the home cooking effect.

We assume there is no difference in air pollution between the pre-CNY days in 2020 and 2018/2019 after controlling for city fixed effects, year fixed effects, month 
fixed effects, day of month fixed effects, and day of week fixed effects. The regression results are reported in Table 3. Compared to the years before 2020, air pollution significantly decreased by $14.9 \%-16.6 \%$ in the sixteen days after the CNY's Eve (Panel A, columns (1) and (3)). After we decompose this post-CNY period into the regular CNY holiday ( $1^{\text {st }}$ to $7^{\text {th }}$ day after CNY eve) and the unexpected COVID shutdown period ( $8^{\text {th }}$ to $16^{\text {th }}$ day after CNY eve), the first period a $27.5 \%$ larger decline in pollution relative to 2018 and 2019, and this extra drop in the second period was $7.1 \%-9.7 \%$ (Panel A, columns (2) and (4)).

\section{// Insert Table 3 about here //}

By estimating equation (5) for each city, we obtain 285 estimates of $\delta_{4}$ and $\delta_{5}$. These measure the changes in air pollution during the CNY holiday and COVID shutdown days of 2020 relative to 2018 and 2019, respectively. Figure A4 present the changes in $\mathrm{PM}_{2.5}$ concentration during the CNY holiday and COVID shutdown days across cities in 2020. Most of Chinese cities (190 out of 285) experienced decreases in air pollution. ${ }^{11}$

\subsection{Understanding Why Pollution Declined in Early 2020 in Many Cities}

We focus on three main determinants of air pollution - driving, industrial activities, and cooking ${ }^{12}$, which were impacted by the COVID shutdown. First, the majority of the trips were cancelled, which would reduce the emission of air pollutants from vehicles. Second, factories were forced to close. This led to a significant reduction in industrial pollutant emissions. ${ }^{13}$ Third, the closure of restaurants and the ban on

\footnotetext{
11 Air pollution in cities in northeast and northwest China increased in CNY holiday of 2020, which might due to some meteorological factors and the weak impact of the initial COVID outbreak.

${ }^{12}$ We do not include coal consumption in explaining the air pollution changes to avoid double counting. Coal is the raw materials of production and living activities. The three activities that we focus on (driving, industrial activities, and cooking) represent the major activities for which coal is used. According to the energy balance sheet of China in 2017, the industrial production itself consumed $94.8 \%$ coal in China. This consumption also includes the coal used for generate power which is used by industrial sector.

${ }^{13}$ Necessary production activities such as power supply, water supply and heating, and production activities of medical supplies related to epidemic control did not stop.
} 
gatherings greatly reduced people's dining out activities. During this time people could only cook at home, and this might lead to increased air pollution due to the decentralized low-efficient use of solid fuels (Chafe et al., 2014).

To decompose recent pollution dynamics into key urban fundamentals, we construct three variables to reflect the driving, industrial activities, and cooking activities in Chinese cities. They are the total number of private cars (in log, Vehicle), GDP share from industrial sector (Industry), and the employment in the accommodation and restaurant industry (in logs, Cooking). We use the pre-COVID levels of the three variables to reflect the city's scale in these three activities. We posit that cities featuring greater levels of transport, industry and cooking before the COVID shutdown would feature higher levels of air pollution.

Panels C-D in Figure A3 plots these associations. The y-axis is the estimate of cityspecific $\theta_{2}$ by estimating equation (4) for each city. As expected, both the number of private cars and the industrial sector GDP share is positively correlated with the $\mathrm{PM}_{2.5}$ drop from the COVID. The number of employees in accommodation and the restaurant industry is negatively correlated with the $\mathrm{PM}_{2.5}$ drop.

We further quantify those associations by decomposing the pollution decline due to COVID into these three factors. We estimate the following equation where region fixed effects are included. The unit of analysis is a city.

$$
\begin{aligned}
{\text { B } \text { ollution }_{i}} & =\rho_{0}+\rho_{1} \cdot \text { Vehicle }_{t}+\rho_{2} \cdot \text { Industry }_{i}+\rho_{3} \cdot \text { Cooking }_{i} \\
& + \text { region fixed effects }+\varepsilon_{i}
\end{aligned}
$$

The results are reported in Panel B in Table 3. We find that among the three activities, cooking mainly contributes to the changes in air pollution in the regular CNY holiday. This result is plausible as most of the production activities stopped during every year's CNY holiday. Therefore, the $\mathrm{PM}_{2.5}$ change in this year relative to the previous years in this regular holiday window was not correlated with the production scale. However, in the post-CNY COVID shutdown days which only existed in year 2020, cities with more private cars, a larger share of the industrial production in the urban 
economy, and fewer people employed in the restaurant sector experienced a larger decrease in air pollution.

\section{Blue Skies as an Experience Good}

We now compare a subset of Chinese cities to the rest of the cities. We focus our attention on the subset of cities that meet two criteria. The first criteria is that the city experienced a 2020 air pollution decline in the COVID pandemic (based on the cityspecific estimate of $\theta_{2}$ in equation (4)). The second criteria is that the city's antipollution sentiment is greater than the median (based on the estimates from Zheng et al. (2019)).

We divide the 144 Chinese cities into four quadrants based on their sentimentpollution elasticity and the $\mathrm{PM}_{2.5}$ change during the COVID shutdown. As shown in Panel A in Figure 2, the 49 cities in quadrant I are those where air pollution significantly declined and the population is more sensitive to air pollution. These cities are defined to be the "treated cities". We examine whether their population exhibits a high demand for clean air. We study this using the Baidu data.

\section{// Insert Figure 2 about here //}

Here we construct a daily Baidu environmental attention index, and estimate the following DID model for city/year/day data.

$$
\text { baidu_index }_{i t}=\eta_{0}+\eta_{1} \cdot \text { Treat }_{i} \cdot \text { Post }_{t}+\text { fixed effects }+\mu_{i t}
$$

In equation (7), the dependent variable is the daily count of the keyword "environment protection" in the Baidu search engine by city $i$ at date $t$. The baidu_index in equation (7) is standardized by dividing it over its mean value. This makes the number comparable across different keywords. Treat equals 1 for the cities in quadrant 
I in Figure 2 Panel A and equals zero for the cities in the other quadrants. City fixed effects and date fixed effects are included in the regression.

The trends in Panel B in Figure 2 show that the quantity of Internet discussion activity mentioning "environmental protection" in Chinese cities in Quadrant I increased by more than in other cities during the same time period. The regression results confirm that this Baidu index in those cities increased 1.5 times of its mean higher than the other cities (see Table A2). The local population in the Quadrant I cities is increasingly interested in environmental protection and they seek more information about what the local officials are doing to further improve the local environment.

\subsection{Local Government Post-COVID Stimulus}

Whether the short-run improvement in air quality persists over time as the local economy recovers hinges on how such a bottom-up push pressure from the local pople nudges the local government to enact credible anti-pollution policies. In this section we investigate whether local governments in 2020 redesigned their environmental strategies and whether this "green push" is stronger for cities in Quadrant I.

Since February 2020, both the central and local governments have issued many different "stimulus" polices aiming to re-boost the economy and make up the economic loss due to the COVID shutdown. In China, local governments have a strong "visible hand" in setting the priorities in local economic growth and allocating resources to implement their growth strategies. They are very good at implementing those industrial policies in a timely fashion (Zheng et al. 2017). Therefore, it is highly likely that those stimulus policies will be implemented as stated.

Some of the stimulus policies highlight the "greenness" and "sustainability", while others do not. For instance, on March 4, 2020, the Standing Committee of the Political Bureau of the CCP Central Committee issued a guideline on speeding up the construction of "new infrastructure"14, e.g., 5G, IoT, big data center, etc., which are much greener than the old infrastructure such as highways and power plants. On

\footnotetext{
14 Source: http://cpc.people.com.cn/n1/2020/0305/c64094-31617516.html.
} 
February 27, 2020, Guangzhou city government issued the stimulus policy of providing financial subsidy measures for the promotion and application of new energy buses ${ }^{15}$. While in Yinchuan city, on March 2, 2020, the city government issued a stimulus policy to boost and stabilize the industrial growth after the COVID pandemic aiming to fulfill the economic growth target set originally. ${ }^{16}$

We collected the policy documents issued by local governments from February 2020 to May 2020 from Bailu ThinkTank (http://www.bailuzhiku.com/policy/adlist), and extracted the stimulus policies related to industrial development. Here we focus on three types of "green industrial policies" - new energy vehicles, industrial upgrading (toward low energy intensity) and new IT infrastructure. ${ }^{17}$ Panel C in Figure 2 shows the statistical results for the four groups of cities presented in Panel A of this figure. We find that those cities in quadrant I have a larger share of their documents mentioning the "green industrial policies". While those cities in quadrant IV have the very low share of pro-environment documents. This is suggestive evidence that the local governments for the quadrant I cities are responding to their citizens' demand for blue sky and are taking actions to strike a balance between stimulating the economy and protecting the environment.

\section{Conclusion}

In early 2020, cities all over the world have experienced an economic shutdown in order to reduce the contagion risk. A silver lining of this shutdown is that previously very dirty cities experienced blue skies. We posit that clean air is an experience good.

The private sector often produces new goods such as electric vehicles or science fiction movies. Before a person experiences such a good, they may under-value it. Anticipating this issue, sellers of such new products will engage in advertising and offer initially low prices to attract consumers. In contrast to a private good, a city's air quality

\footnotetext{
15 Source: http://www.gz.gov.cn/gfxwj/sbmgfxwj/gzsjtysj/content/post_5680165.html. 16 http//www yinchuan.gov.cn/xxgk/bmxxgkml/szfbgt/xxgkml_1841/zfwj/yzbf/202003/t20200304 1978593.html. 17 The policies we consider are all officially published with clearly Issued Numbers. All subordinate offices will receive this document and have to carry out the work following the guidance of the policy document.
} 
is a local public good. It is produced as a byproduct of the activities of emissions within the airshed and that blow into the airshed. A byproduct of China's development fueled by coal and heavy industry production is that there are many cities where ordinary people have not experienced clean air for decades. The 2020 shutdown offered a dramatic regime change.

If the Environmental Kuznets Curve is stable over time, then a "V" shaped recovery for the macro economy would predict that air pollution will return to its previous high levels in cities in polluted developing nations such as China. We have argued that because clean air is an experience good that a silver lining of the recent blue sky episode is to stimulate increased demand for this good. While co-ordination costs often inhibit collective action, in this case the large pollution reduction helps to coordinate urban pressure as each person in a previously dirty city experiences clean air and knows that every other local urbanite is also experiencing cleaner air. Past research on the "silver lining" of environmental disasters in the United States demonstrates that more aggressive pro-environment regulation is proposed in the aftermath of such shocks as Three Mile Island and the Exxon Valdez oil spill (Kahn 2007).

The most novel part of our empirical work uses recent Internet search data and policy document text analysis to test the "clean air as an experience good" hypothesis. We document that Internet discussion intensity related to environmental protection has increased and this increase has been most pronounced in cities which had both been polluted and where there is a latent demand for pollution progress (the subset of cities with the large anti-pollution sentiment elasticity). 


\section{References}

Barwick PJ, Li S, Rao D, Zahur NB. The morbidity cost of air pollution: evidence from consumer spending in China. National Bureau of Economic Research; 2018 Jun 7.

Chafe Z A, Brauer M , Klimont Z, et al. Household Cooking with Solid Fuels Contributes to Ambient [PM.Sub.2.5] Air Pollution and the Burden of Disease. Environmental Health Perspectives, 2014, 122(12):1314-20.

Dasgupta S, Laplante B, Wang H, Wheeler D. Confronting the environmental Kuznets curve. Journal of economic perspectives. 2002 Mar;16(1):147-68.

Grossman, Gene M., Krueger, Alan B. Economic growth and the environment. Quarterly Journal of Economics, 1995, 110(2): 353-377.

He, G., Pan, Y. \& Tanaka, T. The short-term impacts of COVID-19 lockdown on urban air pollution in China. Natural Sustainability (2020).

Hilton F G H , Levinson A . Factoring the Environmental Kuznets Curve: Evidence from Automotive Lead Emissions. Journal of Environmental Economics and Management, 1998, 35(2):126-141.

Ito K, Zhang S. Willingness to pay for clean air: Evidence from air purifier markets in China. Journal of Political Economy. 2020 May 1;128(5):1627-72.

Kahn ME. Environmental disasters as risk regulation catalysts? The role of Bhopal, Chernobyl, Exxon Valdez, Love Canal, and Three Mile Island in shaping US environmental law. Journal of Risk and Uncertainty. 2007 Aug 1;35(1):17-43.

Kahn ME. The silver lining of rust belt manufacturing decline. Journal of Urban Economics. 1999 Nov 1;46(3):360-76.

Liang X, Li S, Zhang S, et al. PM2. 5 data reliability, consistency, and air quality assessment in five Chinese cities. Journal of Geophysical Research: Atmospheres, 2016, 121(17): 10,220-10,236.

Selden, T.M., Song, D., 1995. Neoclassical growth, the J curve for abatement and the inverted U curve for pollution. Journal of Environmental Economics and Management, 1995, 29: 162-168.

Shapiro C. Optimal pricing of experience goods. The Bell Journal of Economics. 1983 Oct 1:497-507.

Stoerk T. Statistical corruption in Beijing's air quality data has likely ended in 2012. Atmospheric Environment, 2016, 127: 365-371.Riordan MH. Monopolistic competition with experience goods. The Quarterly Journal of Economics. 1986 May 1;101(2):265-79.

Sun C, Kahn ME, Zheng S. Self-protection investment exacerbates air pollution exposure inequality in urban China. Ecological economics. 2017 Jan 1;131:468-74.

Zheng S, Kahn ME. A new era of pollution progress in urban China?. Journal of Economic Perspectives. 2017 Feb;31(1):71-92.

Zheng S, Kahn M E, Sun W, et al. Incentives for China's urban mayors to mitigate pollution externalities: The role of the central government and public environmentalism. Regional Science and Urban Economics, 2014, 47(7):61-71.

Zheng, S., Wang, J., Sun, C. et al. Air pollution lowers Chinese urbanites' expressed happiness on social media. Natural Human Behavior, 2019 (3), 237-243. 
Figure 1. Cumulative Distribution Function of Population Pollution Exposure in 2015 and 2019 (weighted by 2015 population)

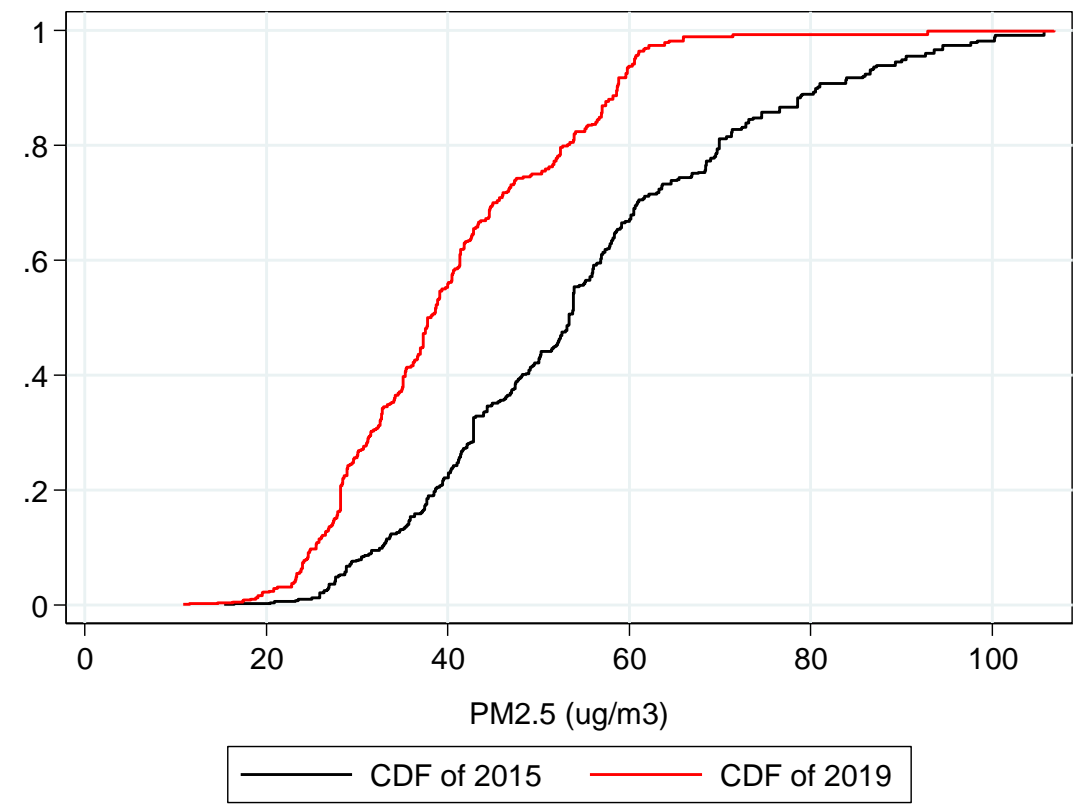




\section{Figure 2. Looking Forward - Blue Skies After COVID}

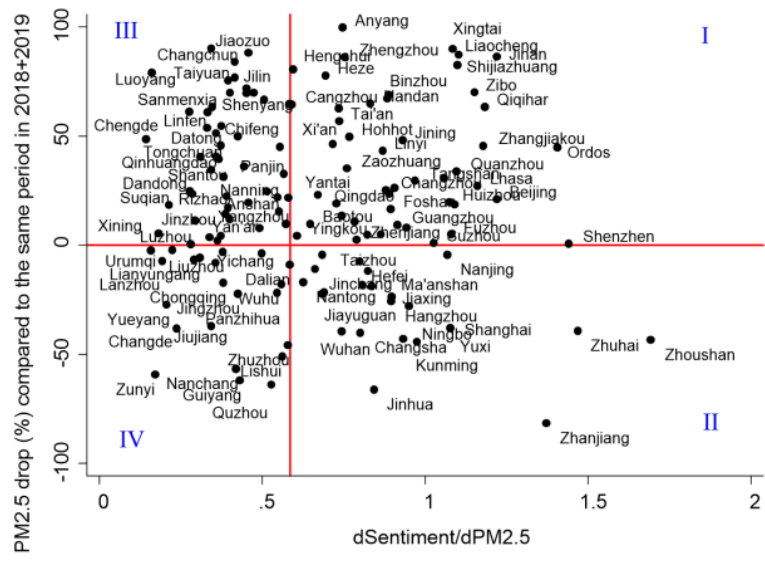

A. Four Quadrant Grouping of Cities

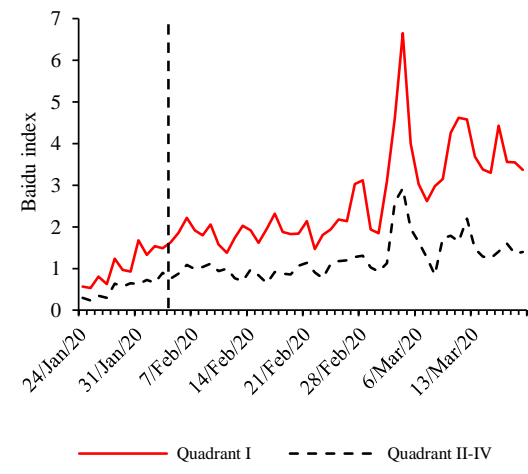

B. Baidu Index in Early 2020

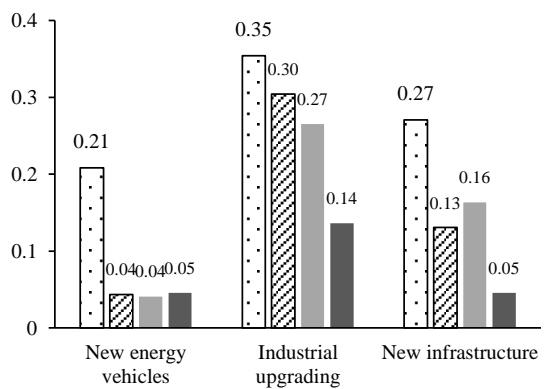

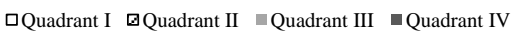

C. Share of City That Implementing the "Green Industrial Policies"

Notes: (1) dSentiment/dPM2.5 is the "sentiment-pollution" elasticities, which is reported in Zheng, S., Wang, J., Sun, C. et al. Air pollution lowers Chinese urbanites' expressed happiness on social media. Natural Human Behavior, 2019 (3), 237-243. (2) The $\mathrm{PM}_{2.5}$ decline during the COVID shutdown is estimated based on the city-specific estimate of $\theta_{2}$ in equation 4. 
Table 1. Trends in the $\mathrm{PM}_{2.5}$ Concentration (144 city-year data, 2015-2019)

\begin{tabular}{|c|c|c|c|c|}
\hline Dependent variables: & $\begin{array}{c}(1) \\
\ln \left(P M_{2.5}\right)\end{array}$ & $\begin{array}{c}(2) \\
\ln \left(P M_{2.5}\right)\end{array}$ & $\begin{array}{c}\text { (3) } \\
\text { Baidu_index }\end{array}$ & $\begin{array}{c}(4) \\
\ln \left(P M_{2.5}\right) \\
\end{array}$ \\
\hline Trend & $\begin{array}{c}-0.080^{* * * *} \\
(0.004)\end{array}$ & $\begin{array}{c}-0.073^{* * * *} \\
(0.005)\end{array}$ & $\begin{array}{l}0.000^{* * *} \\
(0.000)\end{array}$ & \\
\hline High_Sentiment $\times$ Trend & & $\begin{array}{c}-0.013^{* * *} \\
(0.007)\end{array}$ & $\begin{array}{l}0.001^{* * *} \\
(0.000)\end{array}$ & \\
\hline Baidu_index & & & & \\
\hline Lag of.Baidu_index & & & & $\begin{array}{c}-2.288^{* * *} \\
(0.732)\end{array}$ \\
\hline Lag of . $\ln P M 2.5$ & & & & $\begin{array}{c}0.537^{* * * *} \\
(0.048)\end{array}$ \\
\hline Control variables & $\mathrm{Y}$ & $\mathrm{Y}$ & $\mathrm{Y}$ & $\mathrm{Y}$ \\
\hline$N$ & 718 & 718 & 718 & 574 \\
\hline$R^{2}$ & 0.950 & 0.951 & 0.460 & 0.942 \\
\hline
\end{tabular}

Notes: Columns (1), (2) and (4) report results from estimating fitting version of equation 1; column (3) reports results from estimating equation 2. Control variables include temperature, rainfall, and city fixed effects. Robust standard errors clustered at the city level are reported in parentheses. ${ }^{*} p<0.10,{ }^{* *} p<0.05,{ }^{* * *} p<0.01$.

Table 2. Estimates of the Urban Environmental Kuznets Curve

Dependent variable: $\ln \left(P M_{2.5}\right)$

\begin{tabular}{lccccc}
\hline & $(1)$ & $(2)$ & $(3)$ & $(4)$ & $(5)$ \\
& All cities & $\begin{array}{c}\text { High } \\
\text { sentiment }\end{array}$ & $\begin{array}{c}\text { Low } \\
\text { sentiment }\end{array}$ & $\begin{array}{c}\text { High } \\
\text { Baidu_index }\end{array}$ & $\begin{array}{c}\text { Low } \\
\text { Baidu_index }\end{array}$ \\
\hline $\ln \left(G D P \_p c\right)$ & $0.783^{* * *}$ & $0.571^{* * *}$ & $0.677^{* *}$ & $0.429^{* * *}$ & $0.699^{* * *}$ \\
& $(0.078)$ & $(0.148)$ & $(0.296)$ & $(0.155)$ & $(0.160)$ \\
$\ln \left(G D P \_p c\right)^{2}$ & $-0.247^{* * *}$ & $-0.173^{* * *}$ & $-0.218^{* *}$ & $-0.163^{* * *}$ & $-0.175^{* * *}$ \\
& $(0.024)$ & $(0.038)$ & $(0.089)$ & $(0.039)$ & $(0.063)$ \\
Turning point (RMB in 2015) & 48,829 & 49,041 & 47,373 & 37,423 & 73,786 \\
Number. (\%) of cities passing the & 527 & 236 & 173 & 474 & 20 \\
Turning Point & $(47.0 \%)$ & $(82.2 \%)$ & $(60.5 \%)$ & $(83.9 \%)$ & $(3.6 \%)$ \\
Control variables & $\mathrm{Y}$ & $\mathrm{Y}$ & $\mathrm{Y}$ & $\mathrm{Y}$ & $\mathrm{Y}$ \\
$N$ & 1,121 & 287 & 286 & 565 & 556 \\
$R^{2}$ & 0.393 & 0.466 & 0.340 & 0.401 & 0.383 \\
\hline
\end{tabular}

Notes: This Table reports results from estimating equation 3. Control variables include population, temperature, rainfall, and year fixed effects. Robust standard errors clustered at the province/year level are reported in parentheses. ${ }^{*} p<0.10,{ }^{* *} p<0.05,{ }^{* * *} p<0.01$. 
Table 3. The Effects of the Economic Shutdown on Air Pollution and the Determinants of Air Pollution Changes

\begin{tabular}{|c|c|c|c|c|}
\hline \multicolumn{5}{|c|}{$\begin{array}{c}\text { Panel A: The Effects of the Shutdown on Air Pollution } \\
\text { Dependent variable: } \ln \left(P M_{2.5}\right)\end{array}$} \\
\hline & \multicolumn{2}{|c|}{29 province sample } & \multicolumn{2}{|c|}{$\begin{array}{c}28 \text { province sample } \\
\text { (drop Hubei) }\end{array}$} \\
\hline Shutdown & $\begin{array}{c}-0.130^{* * *} \\
(0.022)\end{array}$ & & \multicolumn{2}{|c|}{$\begin{array}{l}-0.120^{* * * *} \\
(0.022)\end{array}$} \\
\hline Shutdown $\times$ year2020 & $\begin{array}{l}-0.149^{* * * *} \\
(0.026)\end{array}$ & & \multicolumn{2}{|l|}{$\begin{array}{c}-0.166^{* * *} \\
(0.027)\end{array}$} \\
\hline SF_holiday & & $\begin{array}{c}-0.092^{* * *} \\
(0.019)\end{array}$ & & $\begin{array}{c}-0.086^{* * *} \\
(0.019)\end{array}$ \\
\hline COVID_shutdown & & $\begin{array}{c}-0.347^{* * * *} \\
(0.032)\end{array}$ & & $\begin{array}{c}-0.331^{* * *} \\
(0.034)\end{array}$ \\
\hline SF_holiday $\times$ year 2020 & & $\begin{array}{c}-0.275^{* * *} \\
(0.030)\end{array}$ & & $\begin{array}{c}-0.276^{* * *} \\
(0.031)\end{array}$ \\
\hline COVID_shutdown $\times$ year 2020 & & $\begin{array}{l}-0.071^{*} \\
(0.037)\end{array}$ & & $\begin{array}{c}-0.097^{* *} \\
(0.038)\end{array}$ \\
\hline Control variables & Y & $\mathrm{Y}$ & Y & Y \\
\hline$N$ & 31,376 & 31,376 & 30,044 & 30,044 \\
\hline$R^{2}$ & 0.392 & 0.399 & 0.391 & 0.397 \\
\hline \multicolumn{5}{|c|}{ Panel B: The Determinants of Air Pollution Changes } \\
\hline & \multicolumn{2}{|c|}{29 province sample } & \multicolumn{2}{|c|}{$\begin{array}{l}28 \text { province sample } \\
\text { (drop Hubei) }\end{array}$} \\
\hline Dependent variables & $\begin{array}{c}\text { Air pollution } \\
\text { change in } \\
2020 \\
\text { Chinese New } \\
\text { Year holiday } \\
\left(\delta_{4}\right) \\
\end{array}$ & $\begin{array}{l}\text { Air pollution } \\
\text { change in } \\
2020 \\
\text { COVID } \\
\text { shutdown } \\
\left(\delta_{5}\right) \\
\end{array}$ & $\begin{array}{c}\text { Air pollution } \\
\text { change in } \\
2020 \\
\text { Chinese New } \\
\text { Year holiday } \\
\left(\delta_{4}\right) \\
\end{array}$ & $\begin{array}{l}\text { Air pollution } \\
\text { change in } \\
2020 \\
\text { COVID } \\
\text { shutdown } \\
\left(\delta_{5}\right) \\
\end{array}$ \\
\hline $\ln ($ Vehicle $)$ & $\begin{array}{l}-0.011 \\
(0.035)\end{array}$ & $\begin{array}{c}-0.114^{* * *} \\
(0.033)\end{array}$ & $\begin{array}{c}0.005 \\
(0.036)\end{array}$ & $\begin{array}{c}-0.105^{* * *} \\
(0.035)\end{array}$ \\
\hline Industry_share & $\begin{array}{l}-0.268 \\
(0.233)\end{array}$ & $\begin{array}{c}-0.583^{* * * *} \\
(0.220)\end{array}$ & $\begin{array}{l}-0.331 \\
(0.237)\end{array}$ & $\begin{array}{c}-0.630^{* * * *} \\
(0.225)\end{array}$ \\
\hline $\ln ($ Restaurant_emp $)$ & $\begin{array}{c}0.078^{* * * *} \\
(0.028)\end{array}$ & $\begin{array}{c}0.095^{* * * *} \\
(0.027)\end{array}$ & $\begin{array}{l}0.068^{* *} \\
(0.030)\end{array}$ & $\begin{array}{c}0.086^{* * * *} \\
(0.028)\end{array}$ \\
\hline Region fixed effects & $\mathrm{Y}$ & $\mathrm{Y}$ & $\mathrm{Y}$ & $\mathrm{Y}$ \\
\hline Constants & $\begin{array}{c}0.509 \\
(0.541)\end{array}$ & $\begin{array}{c}2.345^{* * * *} \\
(0.522)\end{array}$ & $\begin{array}{c}0.265 \\
(0.575)\end{array}$ & $\begin{array}{c}2.160^{* * * *} \\
(0.546)\end{array}$ \\
\hline$N$ & 269 & 269 & 258 & 258 \\
\hline$R^{2}$ & 0.279 & 0.462 & 0.301 & 0.452 \\
\hline
\end{tabular}

Notes: In Panel A, Columns (1) and (3) report results from estimating equation 4; columns (2) and (4) report results from estimating equation 5. Dependent variable is $\log$ of $\mathrm{PM}_{2.5}$ concentration. Control variables include city fixed effects, year fixed effects, month fixed effects, day of month fixed effects, and day of week fixed effects. Robust standard errors clustered at city level are reported in parentheses. Panel B reports results from estimating equation 6. Robust standard errors are reported in parentheses. ${ }^{*} p<0.10,{ }^{* *} p<0.05,{ }^{* * *} p<0.01$. 


\title{
Clean Air as an Experience Good
}

\author{
Online Appendix
}

\author{
Matthew E. Kahn, Weizeng Sun, Siqi Zheng
}

\section{Appendix 1: Data Appendix}

PM2.5 data. We collect the data of $\mathrm{PM}_{2.5}$ concentration from the real time release platform of national urban air quality of China Environmental Monitoring Station. The data is daily released since May $13^{\text {th }} 2014$.

The air pollution data of China in early time was found to be manipulated by local government and inaccurate (Ghanem and Zhang 2014). However, since 2013, the central government of China has issued a series of policies to ensure the quality of air monitoring and avoid data manipulation ${ }^{18}$. More recent studies have documented the improvement of air pollution data quality of Chinese cities. For example, Liang et al. (2016) found that the US $\mathrm{PM}_{2.5}$ monitors show measured values highly consistent with

18 On September 10, 2013, the State Council issued the "Air Pollution Prevention and Control Action Plan" (APPCAP), emphasizing the government's objective of establishing a centrally-managed national air quality monitoring network, which includes the construction of urban stations, background stations, and regional stations. The Plan aims to enhance the management of the quality of monitoring data, objectively reflect the air quality status, strengthen the construction of the online monitoring system for primary pollution sources and promote the application of environmental satellites. By 2015, all cities, at the prefecture-level and above, were equipped with monitoring stations for fine particulate matter and stations under government supervision. Remote quality control systems had been set up in 1,436 national control monitoring stations, with the function of data recording and alarm systems under abnormal circumstances. Fu Deqian, Deputy Head of China National Environmental Monitoring Center, noted that "there are several monitoring stations in one city and the data from all stations should be similar. If the data reported in one station is inconsistent with the others', the alarm will be triggered." (see http://www.chinanews.com/sh/2016/12-10/8089501.shtml)

According to the statistics of the Environmental Monitoring Department of the Ministry of Ecology and Environment, in 2015, there were no cases of data falsification. The "Measures for Environmental Monitoring Data Falsification" issued by the Ministry in December 2015 required local environmental departments to carry out inspection of environmental data quality and punish data falsifications.

In July 2016, the Chinese Academy of Engineering organized a mid-term assessment of the implementation of APPCAP and carried out quality control on the monitoring data, especially the PM2.5 data. By integrating the data from the Ministry of Ecology and Environment, the Chinese Academy of Sciences, the China Meteorological Administration, and relevant scientific research institutes on long-term ground-based positioning observations, comprehensive observations of typical processes, and satellite remote sensing inversion, a variety of technical methods had been used to assess air quality conditions, pollution trends across the country. By comparing the synchronous data of 28 monitoring stations of the Chinese Academy of Sciences, China Meteorological Administration, and other institutions, it is found that the multi-party monitoring data of similar stations indicate good consistency, reveal that the monitoring data is systematic and comparable, and is suitable for evaluation. (see http://www.gov.cn/xinwen/2016-07/06/content 5088795.htm)

In November 2016, the Ministry issued the "Thirteenth Five-Year Plan - Environmental Monitoring Quality Management Work Plan" and "Work Plan About Strengthening the Quality Management of Ambient Air Automatic Monitoring", required 1,436 state-controlled monitoring stations in 338 prefecture-level cities nationwide to transfer their monitoring rights. Through public bidding, the third party firm which wins the bid, will be responsible for the project's operation and maintenance. Meanwhile, all stations are required to install video surveillance systems to plug the loopholes of manipulated data falsification. 
those measured at China's Ministry of Environmental Protection $\mathrm{PM}_{2.5}$ monitors located nearby. Stoerk (2016) compared the air quality data via Benford's Law which suggests that misreporting of air quality data for Beijing has likely ended in 2012.

COVID information. The number of death from COVID comes from the Big Data Analysis Platform of Global COVID Epidemic Situation (https://www.zqai.com/\#/fe/xgfybigdata).

Economic and social data. The data of city-year GDP, population, \% of GDP from industrial sector, number of employment in accommodation and restaurant industry come from China City Statistical Yearbook. The data city-year number of private cars comes from the statistical yearbooks of each province. The data of city-year mortality comes from the statistical yearbooks of each city.

Temperature and rainfall. The city-year average temperature and total rainfall is calculated based on the hourly monitoring data of automatic ground stations uploaded by National Meteorological Information Center.

Baidu index. The Baidu keyword search index is created from the Web tools (http://index.baidu.com/v2/index.html\#/). It provides the city-day entries of each key word in https://www.baidu.com/. The index reflects the public attention on the event corresponding to the key word.

Industrial policy information. The policy documents issued by local governments from February 2020 to May 2020 from are download from Bailu ThinkTank (http://www.bailuzhiku.com/policy/adlist). We employ the text analysis tool to extract the stimulus policies related to industrial development and identify if they are environmental friendly. 


\section{Appendix 2: Figure Appendix}

Figure A1. Trends in the PM2.5 Concentration in Big and Small Cities

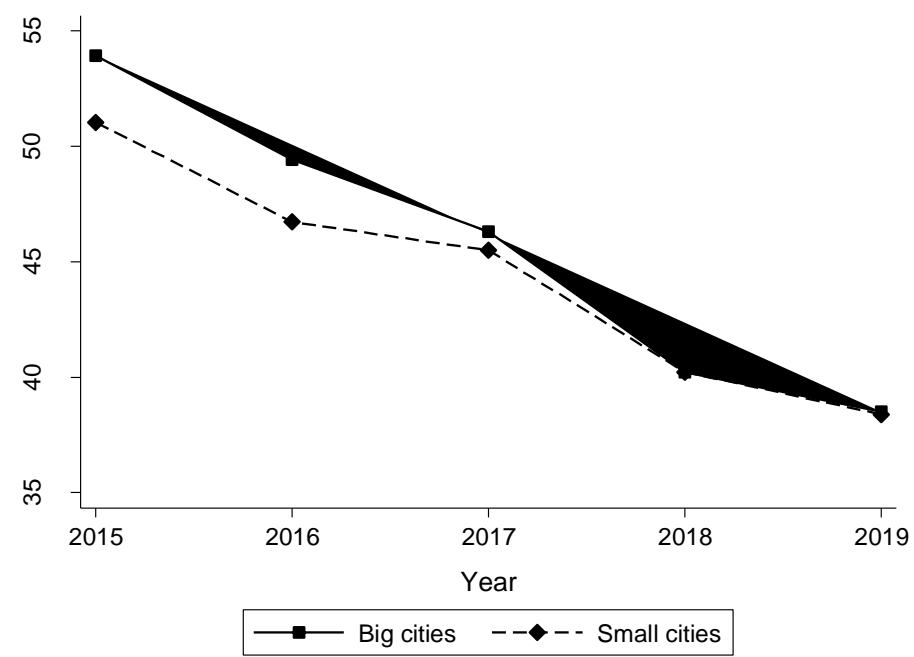

Note: Big cities include 35 major cities in China: Beijing, Tianjin, Shijiazhuang, Taiyuan, Hohhot, Shenyang, Dalian, Changchun, Harbin, Shanghai, Nanjing, Hangzhou, Ningbo, Hefei, Fuzhou, Xiamen, Nanchang, Jinan, Qingdao, Zhengzhou, Wuhan, Changsha, Guangzhou, Shenzhen, Chongqing, Chengdu, Guiyang, Kunming, Xi'an, Lanzhou, Yinchuan, Urumqi; Small cities include other 250 cities in China.

Figure A2. Trends in the GDP Share from Industrial Sector in Big and Small Cities

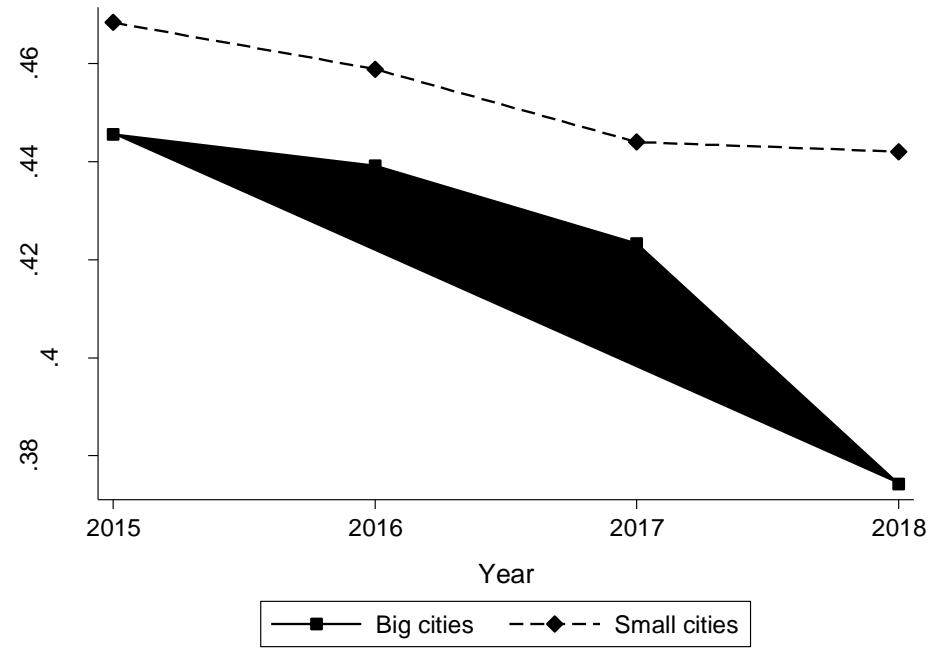

Note: Big cities include 35 major cities in China: Beijing, Tianjin, Shijiazhuang, Taiyuan, Hohhot, Shenyang, Dalian, Changchun, Harbin, Shanghai, Nanjing, Hangzhou, Ningbo, Hefei, Fuzhou, Xiamen, Nanchang, Jinan, Qingdao, Zhengzhou, Wuhan, Changsha, Guangzhou, Shenzhen, Chongqing, Chengdu, Guiyang, Kunming, Xi'an, Lanzhou, Yinchuan, Urumqi; Small cities include other 250 cities in China. 
Figure A3. The Impact of the COVID Induced Shutdown on Pollution Dynamics

A. Timeline of 2020 COVID in China

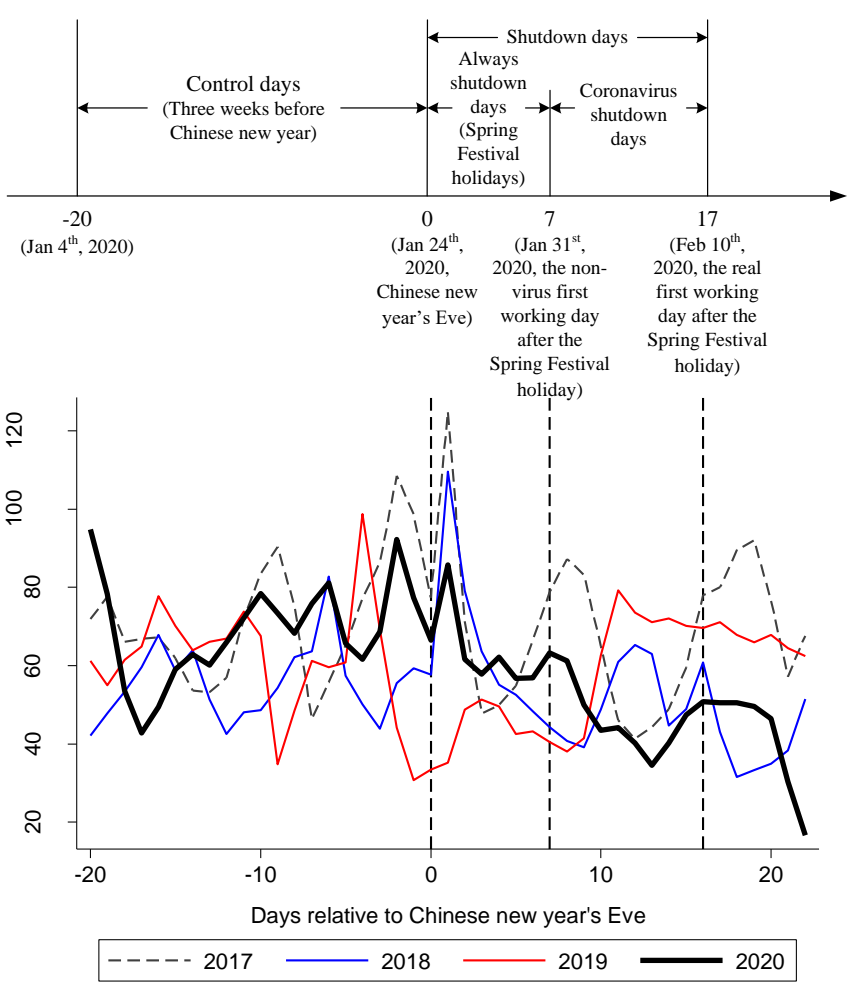

B. Trends of Air Pollution Before and After the Chinese New Year of 2017-2020
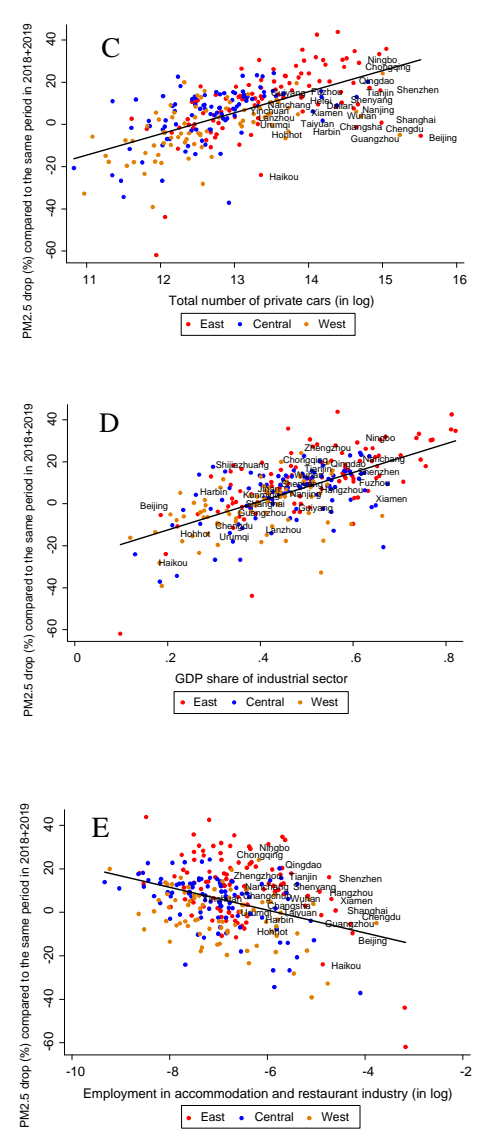

Notes: (1) In Figure 2A and 2B, the left vertical line indicates the 2020 Chinese new year's Eve (Jan $24^{\text {th }}, 2020$ ); the middle vertical line indicates the non-virus first working day after the 2020 Chinese New Year holiday (Jan $31^{\text {st }}$, 2020); the right vertical line indicates the real first working day after the Chinese New Year holiday in 2020 (Feb $10^{\text {th }}, 2020$ ). (2) Figure $2 \mathrm{C}$ reports the relationship between decrease in $\mathrm{PM}_{2.5}$ and number of private cars; Figure 2D reports the relationship between decrease in $\mathrm{PM}_{2.5}$ and GDP share of industrial sector; Figure 2E reports the relationship between decrease in $\mathrm{PM}_{2.5}$ and cooking. 
Figure A4. Changes in $\mathbf{P M}_{2.5}$ during the COVID Shutdown Days

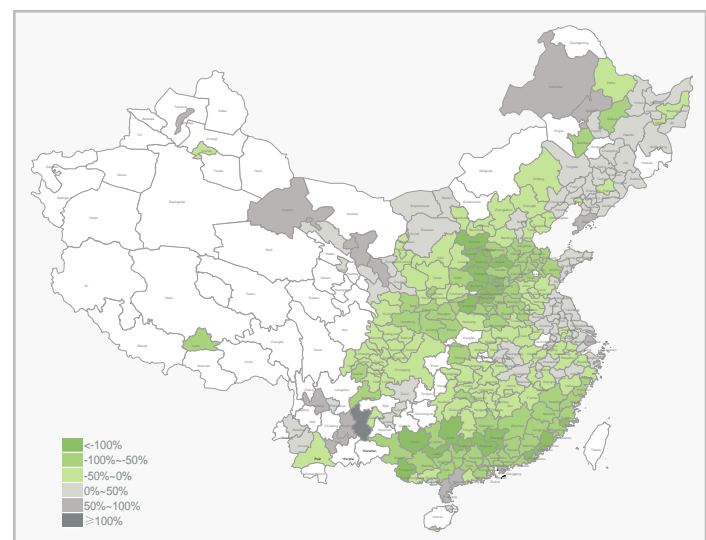

A. Changes in $\mathrm{PM}_{2.5}$ during the Chinese New Year holiday of 2020 ( $\delta_{4}$ of equation 5 )

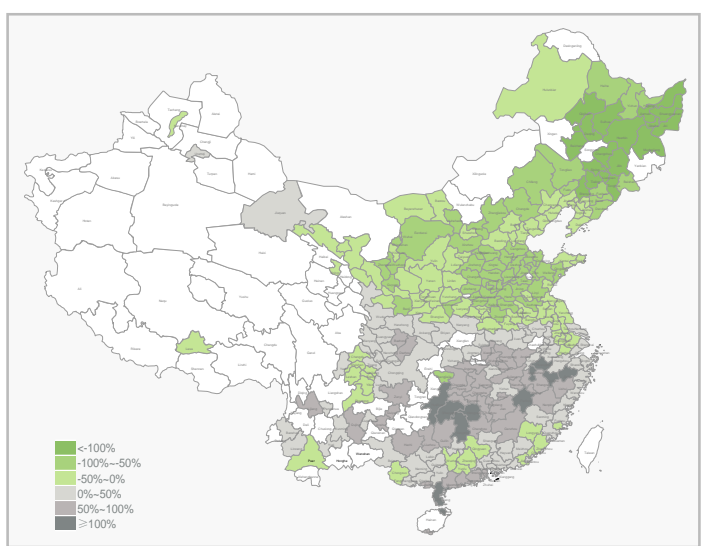

B. Changes in $\mathrm{PM}_{2.5}$ during the COVID shutdown days of 2020 ( $\delta_{5}$ of equation 5$)$ 


\section{Appendix 3: Table Appendix}

Table A1. EKC Results Based on a More Flexible Functional Form for Per-Capita Income

Dependent variable: $P M_{2.5}$

\begin{tabular}{|c|c|c|c|c|c|c|c|}
\hline & $\begin{array}{c}\text { (1) } \\
\text { All cities }\end{array}$ & $\begin{array}{c}(2) \\
\text { Low } \\
\text { sentiment }\end{array}$ & $\begin{array}{c}(3) \\
\text { High } \\
\text { sentiment }\end{array}$ & $\begin{array}{c}\text { (4) } \\
\text { All cities }\end{array}$ & $\begin{array}{c}(2) \\
\text { Low } \\
\text { sentiment }\end{array}$ & $\begin{array}{c}(3) \\
\text { High } \\
\text { sentiment }\end{array}$ & $\begin{array}{c}\text { (4) } \\
\text { All cities }\end{array}$ \\
\hline$X 1$ & $\begin{array}{c}1.292 \\
(1.077)\end{array}$ & $\begin{array}{c}1.131 \\
(1.006)\end{array}$ & $\begin{array}{c}1.719 \\
(2.378)\end{array}$ & $\begin{array}{c}1.105 \\
(0.968)\end{array}$ & $\begin{array}{l}2.613^{* * *} \\
(1.132)\end{array}$ & $\begin{array}{c}-2.729 \\
(2.521)\end{array}$ & $\begin{array}{l}2.427^{* *} \\
(1.027)\end{array}$ \\
\hline$X 2$ & $\begin{array}{c}-2.854^{* * * *} \\
(0.829)\end{array}$ & $\begin{array}{c}-0.300 \\
(1.069)\end{array}$ & $\begin{array}{c}-4.065^{* *} \\
(1.554)\end{array}$ & $\begin{array}{l}-0.566 \\
(1.050)\end{array}$ & $\begin{array}{l}-1.262 \\
(0.961)\end{array}$ & $\begin{array}{c}-2.799^{* * *} \\
(1.173)\end{array}$ & $\begin{array}{l}-1.105 \\
(0.957)\end{array}$ \\
\hline$X 3$ & $\begin{array}{c}-0.678^{* * * * *} \\
(0.255)\end{array}$ & $\begin{array}{c}-2.575^{* * *} \\
(0.629)\end{array}$ & $\begin{array}{l}-0.425 \\
(0.288)\end{array}$ & $\begin{array}{c}-2.498^{* * * *} \\
(0.620)\end{array}$ & $\begin{array}{l}-0.701 \\
(0.499)\end{array}$ & $\begin{array}{c}0.037 \\
(0.355)\end{array}$ & $\begin{array}{c}-1.017^{* * *} \\
(0.475)\end{array}$ \\
\hline$X 1 \times H i g h \_S e n t i m e n t$ & & & & $\begin{array}{c}0.192 \\
(2.750)\end{array}$ & & & \\
\hline$X 2 \times H i g h \_S e n t i m e n t$ & & & & $\begin{array}{c}-4.035^{* * *} \\
(2.026)\end{array}$ & & & \\
\hline$X 3 \times H i g h \_S e n t i m e n t$ & & & & $\begin{array}{c}2.145^{* * * *} \\
(0.701)\end{array}$ & & & \\
\hline High_Sentiment & & & & $\begin{array}{c}2.602 \\
(12.059)\end{array}$ & & & \\
\hline X1×High_Baidu_index & & & & & & & $\begin{array}{l}-2.951 \\
(3.286)\end{array}$ \\
\hline$X 2 \times H i g h \_B a i d u \_i n d e x$ & & & & & & & $\begin{array}{l}-2.319 \\
(1.555)\end{array}$ \\
\hline X3×High_Baidu_index & & & & & & & $\begin{array}{c}0.773 \\
(0.681)\end{array}$ \\
\hline High_Baidu_index & & & & & & & $\begin{array}{c}12.315 \\
(15.178)\end{array}$ \\
\hline $\ln ($ population $)$ & $\begin{array}{c}9.734^{* * * *} \\
(1.006)\end{array}$ & $\begin{array}{c}8.484^{* * * *} \\
(1.082)\end{array}$ & $\begin{array}{c}10.354^{* * * *} \\
(1.160)\end{array}$ & $\begin{array}{c}9.632^{* * * *} \\
(0.874)\end{array}$ & $\begin{array}{c}12.948^{* * * *} \\
(1.270)\end{array}$ & $\begin{array}{l}5.904^{* * * *} \\
(2.161)\end{array}$ & $\begin{array}{c}10.901^{* * * *} \\
(1.100)\end{array}$ \\
\hline Temperature & $\begin{array}{c}-0.345 \\
(0.209)\end{array}$ & $\begin{array}{c}0.143 \\
(0.204)\end{array}$ & $\begin{array}{c}-0.745^{* * *} \\
(0.239)\end{array}$ & $\begin{array}{c}-0.324 \\
(0.204)\end{array}$ & $\begin{array}{c}-0.029 \\
(0.259)\end{array}$ & $\begin{array}{c}-0.914^{* * * *} \\
(0.201)\end{array}$ & $\begin{array}{c}-0.414^{* *} \\
(0.198)\end{array}$ \\
\hline Rainfall & $\begin{array}{c}-0.000^{* * * *} \\
(0.000)\end{array}$ & $\begin{array}{c}-0.000^{* * * *} \\
(0.000)\end{array}$ & $\begin{array}{c}-0.000^{* * * *} \\
(0.000)\end{array}$ & $\begin{array}{c}-0.000^{* * * *} \\
(0.000)\end{array}$ & $\begin{array}{c}-0.000^{* * * *} \\
(0.000)\end{array}$ & $\begin{array}{c}-0.000^{* * * *} \\
(0.000)\end{array}$ & $\begin{array}{c}-0.000^{* * * *} \\
(0.000)\end{array}$ \\
\hline Year fixed effects & $\mathrm{Y}$ & $\mathrm{Y}$ & $\mathrm{Y}$ & $\mathrm{Y}$ & $\mathrm{Y}$ & $\mathrm{Y}$ & $\mathrm{Y}$ \\
\hline Constant & $\begin{array}{l}-0.387 \\
(6.146)\end{array}$ & $\begin{array}{l}-1.485 \\
(8.876)\end{array}$ & $\begin{array}{c}2.383 \\
(10.989)\end{array}$ & $\begin{array}{c}-0.804 \\
(7.186)\end{array}$ & $\begin{array}{c}-28.038^{* * * *} \\
(8.617)\end{array}$ & $\begin{array}{c}48.593^{* * *} \\
(13.409)\end{array}$ & $\begin{array}{l}-11.042 \\
(8.082)\end{array}$ \\
\hline $\begin{array}{l}\text { F test } \\
\text { (p-value) }\end{array}$ & & & & $\begin{array}{c}2.95 \\
(0.023)\end{array}$ & & & $\begin{array}{c}2.33 \\
(0.059)\end{array}$ \\
\hline$N$ & 573 & 286 & 287 & 573 & 285 & 288 & 573 \\
\hline$R^{2}$ & 0.339 & 0.257 & 0.416 & 0.348 & 0.425 & 0.334 & 0.355 \\
\hline
\end{tabular}

Note: Robust standard errors clustered at province/year level are reported in parentheses. ${ }^{*} p<0.10,{ }^{* *} p<0.05,{ }^{* * *}$ $p<0.01$. 
Table A2. Baidu Environment Attention Index (city-day data, January $24^{\text {th }}, 2020$-April $5^{\text {th }}$, 2020)

Dependent variable: Baidu_index

\begin{tabular}{lcc}
\hline & $(1)$ & $(2)$ \\
Key words: & "environment protection" & non-environmental words \\
\hline Treat $\times$ Post & $1.467^{* * *}$ & 0.145 \\
& $(0.593)$ & $(0.252)$ \\
City fixed effects & $\mathrm{Y}$ & $\mathrm{Y}$ \\
Date fixed effects & $\mathrm{Y}$ & $\mathrm{Y}$ \\
Constant & $1.612^{* * *}$ & $1.790^{* * *}$ \\
& $(0.159)$ & $(0.068)$ \\
$N$ & 13,156 & 65,780 \\
$R^{2}$ & 0.691 & 0.522 \\
\hline
\end{tabular}

Note: This Table reports results from estimating equation 7. Robust standard errors clustered at city level are reported in parentheses. ${ }^{*} p<0.10,{ }^{* *} p<0.05,{ }^{* * *} p<0.01$.

We present one placebo test to address concerns about omitted variables that simultaneously affected air pollution and people's environmental attention might bias our DID estimations. To address this endogeneity concern, we further create another five Baidu search index using keywords that are not related with air pollution: COVID19, pneumonia, education, medical treatment, health. Column (2) of Table A2 shows the results of this placebo test. We find a small and insignificant effect on Baidu searches for non-environmental words.

\section{Appendix Reference}

Ghanem D, Zhang J. 'Effortless Perfection:' Do Chinese cities manipulate air pollution data?. Journal of Environmental Economics and Management, 2014, 68(2): 203-25.

Liang X, Li S, Zhang S, et al. PM2. 5 data reliability, consistency, and air quality assessment in five Chinese cities. Journal of Geophysical Research: Atmospheres, 2016, 121(17): 10,220-10,236.

Stoerk T. Statistical corruption in Beijing's air quality data has likely ended in 2012. Atmospheric Environment, 2016, 127: 365-371. 